\title{
My Internship in Malaysia
}

\author{
Binita Gwachha*
}

\section{Introduction to Internship}

Hospitality is the way of treating people in the way you want yourself to be treated. The hotel industry is perhaps one of the oldest commercial endeavors in the world. Internship is one of the methods of on-the-job training which helps an individual to gain the real life experience of the working environment of the profession that $s /$ he is pursuing. It provides an industrial exposure where the individuals can gain a lot of insight about their careers. It is a period of supervised training where the interns or trainees learn practical knowledge and at the same time utilize their theoretical knowledge. Thus, this training period helps to blend in the theoretical knowledge and the practical experiences of the individuals to better understand the career that they are pursing in a professional manner. Internships are ideal for understanding the way a particular industry functions and what it would be like to work in that but. Often, individual who intern with companies are able to gain valuable insights into their own personality and skills. Such experience puts them in a better situation to decide whether they are suited for a particular role within the industry or not. Generally, internship involves a student working in a professional setting under the supervision and monitoring of practicing professionals. It can be paid or unpaid and the student may or may not receive academic credit for performing the internship.

Internship has always been eagerly awaited by the students of any faculty since it provides an opportunity to get exposed with the real working environment of the industry and apply what one has learnt and to learn new things as well as to sharpen skills. It is not just a part of the study but also an important aspect of student's life to see and do experience his her future in the related field. It has both features and advantages of academic and professional life

\section{Introduction of Malaysia and Johor}

Malaysia is like two countries in one, cleaved in half by the South China Sea. While peninsula flaunts bustling cities, colonial architecture, misty tea plantations and chill-out islands, Malaysian Borneo hosts wild jungles of orangutans, granite peaks and remote tribes, along with some pretty spectacular diving. Throughout these two regions is an impressive variety of microcosms ranging from the space-age highrises of Kuala Lumpur to the traditional longhouse villages of Sarawak. Malaysia is a

\footnotetext{
* Binita Gwachha is a student of WhiteHouse School of Hotel Management.
} 
multi-ethnic, multi- religious federation of 13 states and 3 federal territories. Malaysia is ranked $9^{\text {th }}$ in the world and 1st in the Southeast Asia for tourist arrivals. Malaysia boasts one of the south-east Asia's most vibrant economies, the fruit of decades of industrial growth and political stability.

Johor or Johore is one of the thirteen states of Malaysia located in the southern portion of Peninsular Malaysia. Johor Bahru is the capital of this state with a population of over 400,000, and is the country's second largest city. It was formerly known as Tanjung Puteri or Iskandar Puteri. Johor is one of the most developed states in Malaysia. It is surrounded by Pahang to the north, Malacca and Negeri Sembilan to the northwest, and the Straits of Johor to the south, which separates Johor from the Republic of Singapore. After years of being criticized as a dirty, chaotic border town, Johor Bahru, abbreviated as JB, has been repaved and replanted and is well on the way to rebranding itself. There's a handful of worthwhile museums, temples and mosques, shopping and party zones and a heritage district that offers poetic street scenes, hip galleries and playful cafes. JB is conveniently connected to Singapore by the $1038 \mathrm{~m}$-long causeway, and many people choose to work in Singapore and sleep in Johor Bahru.

The state of Johor has more than 150 big hotels, all promising the finest hospitality services and offering state-of-the-art facilities. It houses hotels of various rankings, from simple two stars to highly luxurious five stars. Some of the renowned hotels in Johor Bahru are, Berjaya Waterfront Hotel, Grand Blue Wave Hotel, Hotel Grand Paragon, KSL Hotel \& Resort, Doubletree Hotel, Lego land Hotel, Renaissance Hotel, Thistle Hotel, Mutiara Hotel, The Puteri Pacific Hotel, Hotel Sentral etc. Most of the guests in Johor Bahru come from the neighboring Singapore and Indonesia along with many Malaysian guests.

\section{Introduction to Hotel}

I completed my six months internship in Berjaya Waterfront Hotel, Johor Bahru, Malaysia. The Berjaya Waterfront Hotel is a four star hotel situated in Johor Bahru, Malaysia which is operated and owned by the Berjaya Hotels and Resorts Sdn. Bhd. The Berjaya Hotels and Resorts, often abbreviated as BHR, are managed under the umbrella of Berjaya Groups or also known as Berjaya Corporation Berhad. The Berjaya Corporation group of companies' history dates back to 1984 when Founder, Tan Sri Dato' Seri Vincent Tan Chee Yioun acquired a major controlling stake in Berjaya Industrial Berhad from the founders, Broken Hill Proprietary Ltd, Australia and National Iron \& Steel Mills, Singapore. The company was formerly known as Inter-Pacific Industrial Group Berhad. Berjaya Group Berhad was incorporated in 1967 and is based in Kuala Lumpur, Malaysia. Berjaya Group Berhad operates as a subsidiary of Berjaya Corporation. The hotel operation that comes under the property 
divisions of the Berjaya Corporation Berhad is known as Berjaya Hotels and Resorts. It is a Malaysian chain of luxurious hotels and resorts in Malaysia as well as different parts around the globe. The existing chains of this company are highlighted below:

* Berjaya Times Square Hotel, Kuala Lumpur, Malaysia

* Berjaya Langkawi Resorts, Langkawi, Malaysia

* Berjaya Waterfront Hotel, Johor Bahru, Malaysia

* Berjaya Tioman Resorts, Mersing, Johor, Malaysia

* Berjaya Makati Hotel, Philippines

* Berjaya Beau Vallon Bay Resort and Casino, Seychelles

* Berjaya Praslin Resort, Seychelles

* Berjaya Hotel Colombo, Sri Lanka

* Berjaya Eden Park, London, United Kingdom

The Berjaya Waterfront Hotel, formerly known as The Zon Regency Hotel by the Sea and also called Eden Garden Hotel, is located on the southernmost coastal state of Johor, known as the "Southern Gateway of Peninsular Malaysia “. It is uniquely situated within an integrated duty free shopping and entertainment complex in the Duty free Zone Johor Bahru. The Berjaya Group took over the Zon Regency officially on $15^{\text {th }}$ March 2013, changing name from Zon to BERJAYA WATERFRONT HOTEL. The Berjaya group not only changed the name of the previous hotel but also its exterior outlook. Previously, the entire building was painted with patches of red, blue, white and yellow color, but once Berjaya took over the entire building has been painted completely white. The combination of white paint with its blue windows makes the hotel completely dazzling and gives a royal touch from outside

Ideally situated in the capital city of Johor in Southern Malaysia overlooking the Tebrau Straits, Berjaya Waterfront Hotel, is a international standard hotel blended with the quiet charm of traditional Malaysian culture and hospitality in a rich tapestry of comfort and luxury. The deluxe Berjaya Waterfront Hotel offers stunning views of Johor Bahru from many modern guestrooms. Provision of best hotel amenities coupled with attentive, personalized services etc makes this hotel perfect option for business conferences or family vacation.

The Berjaya Waterfront hotel is located in the business district of Johor Bahru, in the proximity of Woodlands Town Garden, Sultan Abu Bakar Mosque and Grand Palace Park (Istana Besar). This hotel is infrastructural convenient, as it is a mere 10 minutes drive from the central business district, the Johor-Singapore Causeway, the Johor Tourist Information and the Royal Museum, 45 minutes drive from Sultan Ismail Airport, Senai and lhour drive from Singapore International Changi 


\section{Airport}

Conveniently located within the heart of Johor Bahru city, Berjaya Waterfront Hotel is accessible by road from Singapore and is only 5 minutes from the main causeway link between the two borders. It is also in close proximity to the city's Custom \& Immigration Quarantine Complex, Railway Station, Central Business District, and Iskandar Malaysia Southern Development Corridor. There is also plenty of transportation options to get to the Berjaya Waterfront, Johor Bahru. The options are described below:

\section{By Bus}

$>$ Bus numbers: 10A, SS, 22, 123, 507A

\section{* By Car}

$>10$ minutes from Singapore Causeway

$>15$ minutes from North-South Highway ( Tebrau Exit)

$>45$ minutes from Senai International Airport

$>1$ hour from Changing International Airport, Singapore

\section{By Ferry}

$>90$ minutes from Batam Island, Indonesia

$>150$ minutes from Bintan Island, Indonesia

Berjaya Waterfront Hotel, also called BWH, is a contemporary 16 storey hotel with 400 guest rooms, including 318 deluxe rooms, 49 club deluxe rooms, $15 \mathrm{club}$ suites and 15 corner suites. The hotel is elegantly well-furnished with array of amenities having accommodation floors from the $8^{\text {th }}$ floor to 16 th floor. The 13 th and 14 th floors are the smoking prohibited area whereas the rest of floors are allowed for smoking. It has well-appointed guestrooms overlooking the Johor city, Singapore with Johor Strait and the Royal Palace. All the guest rooms are well decorated with air-conditioning control, direct-dial phone with voice mail or messages system, remote controlled multi- channels television and radio, well-stocked mini-bar, coffee and tea making facilities, electronic safe and hair dryer. All the suites room has dining or living room with kitchenette. The Club Floor has a private club lounge, complimentary coffee or tea and a selection of local and international newspapers and magazines. The guestrooms have premium bedding and down comforters that invites a comfortable night's sleep. The bathrobes and free toiletries are also available.

The Berjaya Waterfront offers a wide array s of recreational options. The guest can relax by the swimming pool; get pampered with soothing spa treatments and 
work out at the Fitness Center. The fitness center comes with world-class gymnasium equipment, a steam room and spa.

Besides these, the BWH also provide different choices of dining and entertainment ranging from casual to cosmopolitan. The dexterous in-house restaurants and bars setting a vibrant food, dining and nightlife scene, guests are in for complete and flavorful dining experience. Be it breakfast, brunch, a light mid-afternoon indulgence or even boisterous dinner gatherings, the BWH put together fine cuisine and exquisite beverages that will satisfy even the most discerning of palates. With sumptuous cuisine choices, a unique and welcoming dining ambience and sweeping views of the Johor Straits, dining is always a pleasure at Salt 'n" Pepper Café Restaurant. Featuring distinct local favorites and delectable international cuisine, the outlet also puts forth delightful weekend themed buffet spreads to entice, making it one of the best restaurants in Johor Bahru to dine at.

Stepping into the Lotus Garden Chinese Restaurant, one will discover a warm and welcoming oriental hideaway where traditional furnishings and ornaments beautifully set the mood for a wonderful dining experience. This restaurant offers the taste of authentic Chinese cuisine from different provinces all over China executed to perfection as well as unique and innovative new creations skillfully crafted by the restaurant's specialty chef. Similarly the Palm Lounge and Bistro along with The Club provides mouth watering snacks as well as different cocktails and cocktails, liquors, beers and many more alcoholic beverages. These lounges are well equipped with live bands where the guest can enjoy their favorite drinks with the live band performances.

More than just a place to get coffee, Coffee Bar provides a welcoming and intimate space to bring people together and let conversations flow. To be set apart from other cafés in Johor Bahru, the coffee bar take pride in being a cosy gathering place and are dedicated to maintain this feeling. This outlet offers a warm cuppa and wins over with delectable assortment of freshly baked pastries and sweet treats.

Lastly for entertainment, the guest can go to the Club for live band performance by the LOVE NOTE BAND. Apart from music, the guest can go for shopping in the Zon duty free shops with varieties of liquors, chocolates and perfumes.

The top level management of the Berjaya Waterfront Hotel has been enlisted below.

Berjaya Waterfront Hotel has a very proactive and co-operative team of front office staff, who are always fully dedicated to provide the best and prompt service to the customers. Every guest was welcomed with a warm smile, and attended with care and courtesy. All the staff and trainees worked together in creating a wonderful ambience for the guests. 
There were two receptions in the Berjaya Waterfront Hotel. The main reception was on the ground floor at the main entrance of the hotel, while the other reception was on the sixth floor that was easily accessible from the parking area, which operated from 10 in the morning till 6 in the evening. The entrance of the Berjaya Waterfront Hotel starts from a beautiful porch. This is where the valets receive the guests' vehicles, and bell boys welcome the guests and handle their luggage. Then the guests are received by the front office attendants at the reception counter. The front lobby is connected with the ZON Duty Free Shopping Mall. So, guests could directly enter from the shopping mall as well.

In Berjaya Waterfront Hotel there are nine different $F \& B$ outlets each unique and different from one another in terms of service style, ambience and type of guests that visit. The overall operations of the F\&B department were managed by the F\&B Manager Mr. Izwandy Bin Nordin. He was quite young, charismatic, friendly and proactive. Likewise, the Assistant F\&B Manager Mr. Alwi was also very much proactive and innovative. He was very strict as well and did not allow anyone to sit ideally. However, he was very experienced as well, and shared his memories and knowledge, which was quite helpful and inspiring. Apart from them, there were many outlet managers, supervisors and senior staffs who were always there to guide us in order to perform every work effectively.

All in all, the Food and Beverage Service Department in the Berjaya Waterfront Hotel was quite big and busy. Apart from the daily business of the various restaurants, the F\&B outlets used to organize various events on special occasions as well, like on the Ramadan month, Hari Raya Festival, Labour's Day etc. There were big event halls in the banquet which used to conduct many big events like wedding ceremonies, meetings and conventions, government seminars, etc. All the $\mathrm{F} \& \mathrm{~B}$ outlets of the Berjaya Waterfront Hotel are focused towards providing world-class service to the guests. They provide highly professional service so as to ensure that the guests have a wonderful time while they dine and get fully satisfied of their meal experience. The $\mathrm{F} \& \mathrm{~B}$ outlets in the Berjaya Waterfront Hotel give high priority to the customers as they are well aware that satisfied customers bring repetitive business which helps in the increment of the overall profit of the business. Apart from the world-class service, each of the outlets also reflects a wonderful and elegant ambience for the customers to have the best time of their life with their friends and families.

\section{My Experience during Internship}

Me and my eight other friends were selected to do intern in this four-star Hotel through the process of interview. My training commenced from 11th April to 8th

October 2015. During this exposure, I got acquainted with the operational working environment of the hotel that aids in sharpening my skills and abilities to widen my 
knowledge. Under this internship program, I was given opportunity to be exposed in all major departments of Hotel which are listed d below:

$>$ Front office department

$>$ Food and beverage service department

I got the opportunity to work as a front desk agent in the front office for four months. Then I was transferred to the Food and Beverage Department where I worked in the Coffee Bar and Palm Lounge and Bistro. My entire experience of the internship was really abounding as I was able to get insights of the daily and vital operations of the hotel. It also gave me opportunity to interact with the guests more directly and portrayed a clearer picture about the professional career in the hotel industry. Through this industrial training also learned how to identify different shortcomings and challenges during day-to-day operations, and how to deal with them in an effective and efficient manner. Hence, it was a phenomenal experience that I will enshrine for the rest of my life.

Front Office department was the first department assigned to me and my other 3 friends by the training manager. On the first day, we were given information about the department by front office manager and introduced to all. Then, we were given a quick tour to the hotel rooms by Assistant front office manager, Ms. Rohani Binti Yacob explaining the types of room and its amenities. Learning in this department was a worth since this department allowed us to learn every details of the day to day operation. While working in this department, I worked as front desk attendants. In Berjaya Waterfront hotel, front desk attendants also perform the work of receptionist as well as front office cashier.

The best thing about this department is that they provide opportunity to the trainees to get acquainted with the Property Management System (PMS) of the hotel. They used the OPERA PMS Version 4.0. Firstly, they gave us a manual regarding the instructions to use the software. Then, the IT department provided username for the software which is required for using the software. At the beginning, it was very difficult to cope with software. Gradually, it becomes easier to use it. During my training period, I encountered with communication problems and biases since the staffs prefer to communicate with their own native language rather than English. This department demands a lot mental alertness and can prove to be very stressful. Beyond these, the whole experience in working front office department was over-whelming.

Some of the duties and responsibilities that I performed as a Front Office Attendant are as follows:-

\section{Morning Shift (7am to $3 \mathrm{pm}$ )}

Read the display board for the day's information. 
Attend briefing from the duty manager for any important information.

$>$ Takeover shift from the staff of night shift and follow-up.

$>$ Read the log book for any things to consider.

$>$ Receive handover float money from the duty manager and count to ensure.

$>$ Ensure the printers and credit card machines are functioning.

$>$ Log in OPERA and open the cashier account.

> Print backup reports, like:-

- Guest in-house by room

- Vacant clean rooms

- Departure list

- Arrival list

- Open balance all

- Guest ledger

- Not posting allowed

If everything is ready, then check departure docket and ensure all billing and supporting are attached to the departure registration card. Inform the duty manager if any of the Letter of Understanding (LOU) or supporting is missing.

$>$ Follow up daily traces.

$>$ Perform guest check-out. Ensure all the bills are fully settled and handover any deposits left.

$>$ Follow up departure at 12 oclock; inform the guest that check-out time is at 12 o'clock.

$>$ Input into the system if guest request for Late check-out (LCO).

$>$ Check the arrivals for the day.

$>$ Co-ordinate with duty manager to assign rooms and prepare keys for the groups.

$>$ Perform check-in by following all the necessary procedures.

$>$ At the end of the shift print journal of all the transactions that have been made in the morning shift.

Verify the journal report with the copy of transactions and close the cashier account. 
> Handover the journal report and transactions to the duty manager and get it checked and approved. Then drop it in the daily transactions box.

$>$ Count the float and hand over to the afternoon shift.

$>$ Follow up with the duty manager and take permission to leave.

$>$ Call security for dropping the money in the safety box

$>$ Drop the money in presence of the security and then sign out.

\section{Afternoon Shift (3pm to $11 \mathrm{pm}$ )}

$>$ Greet everyone and read the display board for the day's information.

$>$ Attend briefing from the duty manager.

$>$ Takeover shift from the staff of morning shift, and follow-up on any important issues.

$>$ Receive the float money from the duty manager and count it.

$>$ Log in OPERA and open cashier account.

$>$ Print all the back-up reports for the afternoon shift.

$>$ Check all the FIT and group arrivals.

$>$ Follow up daily traces for any important information.

$>$ Check-in guests as per the hotel's procedures.

$>$ Attend to guest complaints and requests.

$>$ If guests want extra bed or extra housekeeping amenities then inform to the housekeeping. Similarly, if guest complain about problems like AC, TV not functioning then inform the maintenance department to solve it.

$>$ If the guest wants to change his/her room then inform the duty manager and accordingly provide a new room if available.

$>$ Prepare manual charge for various travel agencies' bookings.

$>$ At the end of the shift print journal of all the transactions that have been made in the afternoon shift.

$>$ Verify the journal report with the copy of transactions and close the cashier account.

$>$ Handover the journal report and transactions to the duty manager and get it checked and approved. Then drop it in the daily transactions box.

$>$ Count the float and hand over to the night shift.

$>$ Follow up with the duty manager and take permission to leave. 
Call security for dropping the money in the safety box

$>$ Drop the money in presence of the security and then sign out.

\section{Night Shift (11pm to 7am)}

$>$ Greet all and read the display board for the day's information.

$>$ Attend briefing from the duty manager.

$>$ Takeover shift from the staff of afternoon shift and follow-up.

$>$ Receive the float money from the duty manager and count it.

$>$ Ensure the printers and the credit card machines are properly functioning.

$>$ Log in OPERA and open cashier account.

$>$ Print the arrival report. Check the arrival docket. Print registration form in advance if there is no form in the docket so that later when guest come checkin can be done more quickly.

$>$ Print the departure report for the next day and guest in-house by room.

$>$ Check all the registration forms of the guests that have checked in on that day. Arrange all the forms in the guest in-house docket as per the floor. Also take out all the forms of the guest who will be checking out the next day. Attach the bills behind the registration card. Put all the departure registration forms in the departure docket as per the floor.

After 12 am if there is no guest in the lobby, then switch off most of the lights.

> Print out the Letter of Understanding (LOU) for the online bookings for the next day's arrival and attach it with the registration form in advance. Put all of them in the arrival docket as per the alphabetical order.

$>$ Close the valet posting at around 1:30 am once the valet brings the drop money and closing record. Then print the back-up reports.

- Guest in-house by room

- Vacant clean rooms

- Departure list

- Arrival list

- Open balance all

- Guest ledger

- Not posting allowed 
It is very important to print all these reports because when the PMS system is closed for the day one cannot access anything in the system.

$>$ Print journal of all the transactions that have been made before closing the system.

$>$ Verify the journal report with the copy of transactions and close the cashier account.

$>$ Print the journal of all the staff.

$>$ Inform the duty manager so that s/he can close the PMS for the day.

$>$ Handover the journal report and transactions to the duty manager and get it checked and approved.

$>$ Tally and verify journal of all staff with all the daily transactions of the day. Sort the transactions like payment, paid out, master, visa, cheque, city ledger etc. Bundle them separately with their sorting and current date. Photocopy the journal transaction of all. Get it approved by the duty manager. Then tie all of them into one bundle referring as the daily transaction. File the photocopy into the journal record book.

> As soon as the PMS system restarts for the next day print the breakfast report, newspaper report. Give the newspaper report to the bell desk and the breakfast report to the main restaurant or F\&B department.

$>$ Clean the counter and keep it neat and tidy. Remove unnecessary or waste papers, top-up all the stationery items for the morning and afternoon shift.

$>$ Prepare breakfast vouchers and key card holders for the day's group arrival, if there is enough time.

$>$ At 6 am turn on all the lights.

$>$ Perform check-outs for the guests leaving early in the morning.

$>$ At the end of the shift, print journal of all the transactions that have been made in the morning.

$>$ Verify the journal report with the copy of transactions and close the cashier account again.

$>$ Handover the journal report and transactions to the duty manager and get it checked and approved. Then drop it in the daily transactions box.

$>$ Count the float and hand over to the morning shift.

$>$ Follow up with the duty manager and take permission to leave.

$>$ Call security for dropping the money in the safety box

$>$ Drop the money in presence of the security and then sign out. 
The Relief Shift (12pm to 8pm) is generally provided after performing night shift for a week. This shift is less stressful and thus allows the staff to take some relief in work after a long night's week.

I completed my last two month of internship in F\&B service department. When I first came from the Front Office to the F\&B Department I found a swift change in the way the department operates. I was quite excited and nervous as I was going to a completely different department and entering a new atmosphere with new faces to work with. Firstly, I was transferred to Salt 'N' Pepper restaurant. Then after a week, I was again transferred to Coffee Bar overlooking Palm Lounge and Bistro as well. Working in F\&B service department demands more physical strength than mental. I had this opportunity of learning the POS System i.e. Micros. In this department, I learnt how to make basic hot beverages, to dispense draught beers, punching orders in micros, preparing and settling bills, handling customers and their complaints and preparing daily reports.

Working in this department made me more confident. The assistant managers and outlet manager were very cooperative and helpful. They tried their best to put forth in our training so that we could get more exposure and learning many things as possible. I, mostly worked in morning shifts in this department. Usually, the morning shifts operates the operation of Coffee Bar and Palm Lounge. Besides these two outlets, I was lucky enough to work in all the other F\&B outlets as well, but as a part-timer. I got a lot of part-time opportunities. I managed my time to work in other outlets as well and learn about the operations of the other outlets. Every outlet had its own theme and ambience, and the type of guests coming to dine also varied. Therefore, I got the opportunity to deal with various types of guests and experience different service styles and ambience. In that time period I also got the opportunity to get familiar with a lot of staff. I learned a lot from the experiences they shared and thoroughly enjoyed my final days at the Food and Beverage Service Department.

The daily activities that I performed while working in the coffee bar are listed below:

- Collect keys from security for bistro entrance, coffee bar, palm lounge and lounge cabinet along with safe 72

- Take float money from operator room.

- Put the float money at the coffee bar and palm lounge

- Read briefing book for information

- Wipe all the display cabinets and tables at coffee bar, palm lounge and bistro and side table for lamp

- Receive the pastries, breads, cakes and buns. Put the proper name tag for all the pastry items. 
- Make sure if have guest at the coffee bar, staff must stand by at the coffee bar.

- Arrange all tables and chairs at palm lounge and bistro

- Check sofa and chairs along with the tables for any damage or shakiness.

- Check items unavailable for foods and beverage.

- Turn on the soft music during afternoon

- Check mise-en-place for coffee bar and all stations in coffee bar, palm lounge and bistro.

- Refill sugar- bowl at all station

- Prepare glassware and ice-buckets at all stations required during operation

- Top-up beer mugs inside freezer at all section.

- Prepare at least 3 wine buckets in front of the nar to chill wine if any order

- Clean the side station drawer to make sure no rubbish and left-over food inside the drawer.

- Wipe tent-card at all tables

- Place ashtray on all table at coffee bar, palm lounge and bistro

To explain my experience in words is very difficult. Though my internship period is for short period of time, but working in Berjaya Waterfront hotel made it a complete worth. Unlike other hotels, BWH never pushed their trainees limited to the back of the house doing petty things. Instead they encouraged their trainees to be in the front to see the operational works as clear as water. In most of the hotel, trainees are rarely allowed to perform in the daily operations of the hotel. But, in Berjaya Waterfront, trainees are trained mostly through the method of on the job training. Firstly, they taught us about process and procedure of the job and allowed us to carry out the tasks under proper supervision. This Hotel is successful in imparting sense of responsibilities on trainees and encourages them to perform well. We made mistakes and they taught us through. I get chance to broaden up my knowledge and sharpen my skills through the interaction with professionals and guests. I had this experience of working in real work environment with professional experts in a good working environment. This internship also helps to bring best out of me. It made me more hospitable, hard working, courteous and sincere. Also, it enhances my creative and tactical abilities to deal with people individually and in mass. They handover the operation of entire shift to the trainee under the supervision of the managers which made us more confident and knowledgeable regarding how to run an operation. We faced the guest complaints but we tried to solve that comes within our understandings. If not, we would seek our supervisor to handle the situations. The six months period 
is very short to understand everything but, everything we learnt during this period equals to an achievements.

\section{Problems Faced During Internship}

Apart from a good learning experience, we faced different kinds of problems during internship. The first one is communication problem. Malay- officially known as Bahasa Malaysia- is the official language of Malaysia and is spoken in neighboring Indonesia, Singapore, Thailand and Brunei. As a result, most of the hotel staffs are least conversational in English. The hotel staffs and most of the guest preferred speaking in their own native language as they are not able to speak fluent English, neither did they understand properly. Except for few managers most of the staff lacked in speaking good English. So, at times it was very difficult to understand what they were trying to say, and was equally difficult to make them understand what we were saying. The guest would also prefer to communicate with local staffs and Indonesian trainees that pushed us little behind in our attempt to learn. The hotel should work on to provide language training to the staffs or hire staffs that are fluent in English, at least. This will not only help in better communication between staffs from different countries but also help in providing quality service to the international guests.

Secondly, though the staffs were pretty co-operative but they tend to depend on trainees for their works that created unnecessary pressure or workloads on the trainees. Some staffs tried to do discrimination with expatriates on the work as well as off the work. This is the first time when we encountered the feeling of racism and cultural differences. In major departments, there was not enough permanent staff especially in the F\&B department. So, whenever there used to be big events the hotel had to bring in a lot of part-timers. The part-timers were not much skilled and used to work irresponsibly at times. They did not care about the standards of the hotel and some used to work without sincerity towards the job. Therefore, the hotel should look towards hiring more permanent staff and bring well qualified part-timers who have at least basic knowledge of service and hospitality. The issue of part-timers was there in almost every department. There was very few permanent staff throughout the hotel. So, the hotel should not only look after saving cost but should hire more permanent staff, as they will be more responsible than the part-timers and offer better service. 